\title{
Competitividad en el sector industrial salvadoreño, 1988-1990
}

\author{
Ana Yolanda Morán \\ Linet E. Contreras
}

\section{Introduccion}

La reconversión industrial en nuestro país es hoy en dia un lema de gran actualidad. El fenómeno está teniendo lugar en el marco del delerioro que presenta la economia y la necesidad impostergable de una reinsersión en la economía mundial en parte ante los cambios que han tenido lugar en los últimos anos en el concierto intemacional, con la globalización, la formación de bloques económicos y el avance tecnológico, que están produciendo un contexlo tolalmente diferenle, en el que la capacidad de una reinserción exilosa se vuelve cada vez más difícil.

En esle ambienle, la compelitividad intemacional juega un papel preponderanle, y el conocimiento de ésta debe ser prioritaria para la loma de decisiones al delinir estrategias que lleven al desarrollo de un proceso adecuado de reconversión industrial. Con el presente trabajo, se pretende delinir en forma cuantitativa una aproximación sobre el nivel de competitividad internacional de la industria salvadorena, y asi plantear algunos elementos de análisis que sirvan de base para llevar a cabo ese proceso.

En una primera parte, se define el término competitividad internacional y se identifican sus determinantes básicos; luego se realiza una evaluación de la capacidad de la industria salvadoreha para competir en el mercado internacional y delender su participación en el mercado interno frenle a la penetración de importaciones. En tal sentido, el trabajo se orienta a evaluar y analizar la capacidad competiliva actual de la indus- 
Iria salvadorefia a Iravés de indices cuantitativos que permitan establecer una primera aproximación sobre este aspecto, con lo que se pretende dar elementos base para realizar estudios con mayor protundidad, especialmente de aquellas ramas industriales que se identifiquen como capaces de compelir en el mercado nacional e internacional y/o que presente un polencial exporlador.

\section{Aspectos teóricos sobre compelltivlded Internacional}

\subsection{La compelltivldad: concepto y determinantes}

La compelitividad internacional de un pals "eslá asociada a la capacidad de exportar y de defender el mercado doméstico trente a la penetración de produclos importados" (Salazar, 1990, p. 25). Por consiguienle, la competitividad vendría a ser un reflejo del nivel de eficiencia de una induslria y/o de una rama en particular, en tanlo la eficiencia del sector manufacturero se defina como aquella que "permita satisfacer actual y polencialmenle la demanda doméslica de consumo, y además vender al exterior una cantidad suficiente de sus produclos para pagar las importaciones requeridas por la nación" (Cortial, 1989, p. 49). Por lo tanto, podemos decir que la industria manufacturera será competitiva si es eficiente y será eficiente en tanto sea competitiva.

Los factores que confluyen en el logro de la competitividad de una industria o empresa pueden modificarse endógena o exógenamente. ${ }^{1}$ Los lactores exógenos o estructurales corresponden al entomo compelilivo (la fortalezas y estrategias de otras empresas y paises) y el entorno de políticas gubernamentales, lactores sobre los cuales las empresas tienen poca capacidad de influir. Los factores endógenos incluyen las variables que una empresa puede manejar direclamenle para desarrollar una estrategia competiliva, tales como su geslión empresarial y tecnologica, control de calidad, publicidad, diseno, etc.

El conjunto relativamente complejo de determinantes de la competitividad de una economia se puede clasificar en tres niveles básicos:

1. El nivel global o macroeconómico, que contempla la configuración de las condiciones óplimas para el desarrollo de la induslria;

2. El nivel subsectorial, donde lenemos los faclores especílicos que influyen en la competitividad de cada subsector; $y$

3. El nivel de empresas individuales, que incluye los lactores bajo el

1. Para mayores delalles véase INCAE (1991, pp. 58-62) 
control de cada empresa y que le permiten a ésta definir su estralegia competiliva.

Salazar (1990. p.31) ha identificado ocho áreas estratégicas de acción, en las que se agrupa exhaustivamente los determinantes de la competitividad:

1. Gestión de Calidad

2. Gestión Administraliva y Gerencial

3. Crédilo, Finanzas y Gestión Financiera

4. Gestión de Mercado y Mercadeo

5. Organización de la Producción

6. Gestión Tecnológica

7. Precios y Dislorsiones

8. Recursos Humanos: Entrenamiento y Capacilación

Los tres niveles de acciones de política enunciados anteriormente y las ocho áreas estratégicas, demuestran el complejo conjunto de factores que explican y determinan la competitividad.

\subsection{Indicadores de competitividad internaclonal}

Pueden distinguirse dos sentidos diferentes en que se utiliza el término competitividad y que dan lugar a diferentes indicadores para medir este concepto: uno, como medida del resullado en el desempeno comercial; y dos, como evolución de los factores o atributos críticos que alectan ese resuliado; es decir, precios, coslos, tipos de cambio, elc.

Para analizar la competitividad internacional conviene, en primer lugar, definir la competilividad por su resultado, es decir, por la participación de las exportaciones en el mercado mundial, o por la capacidad de mantener la participación en el mercado doméslico ante un proceso de apertura comercial. Para este fin, se utilizan indicadores tales como el coeficiente de exporlaciones, penetración de las importaciones, los saldos del comercio exterior, la competilividad aparenle y otros. Estos indicadores son muy discutidos en cuanto a su poder explicativo - del por qué se da uno u otro resultado en el desempeno comercial-, pero brindan una aproximación cuantilativa para estimar las ventajas competitivas en el comercio inlernacional. Se enmarcan dentro de un conceplo asociado a la capacidad de una industria en particular para defender su participación en el mercado interno. Asimismo, nos proporcionan un diagnóslico base para el estudio más específico de acuerdo a los resullados oblenidos.

En cuanto a los factores que afectan el desempeno comercial, tenemos un enloque tradicional y otro que llamaremos moderno. El enloque 
Iradicional sobre competilividad es el que involucra los precios, los coslos y el lipo de cambio. Se basa en un modelo en el cual la evolución de la participación de las exportaciones de un pais en un mercado es lunción únicamente de la evolución de los diferenciales entre sus precios de exportación y los precios de sus competidores en ese mercado. Esto supone que los mercados internacionales de bienes transables son allamente sensibles a cambios en los precios; es decir, los "factores no precio", tales como calidad, gestión de mercadeo, especialización, organización de la producción y otros, no se alteran al modificarse la competitividad precio y, por lanlo no se tienen en cuenta en el indicador utilizado. Sin embargo, durante los ańos setenta, una serie de esludios empíricos mostró la relevancia de los factores no precio en la explicación de la competitividad internacional. ${ }^{2}$

Este trabajo se centrará en el análisis de los indicadores que miden en forma cuantitativa el nivel competitivo de una industria. El resultado oblenido tendrá el carácter de una aproximación bastante gruesa sobre la capacidad de los productores locales para compelir en los mercados domésticos y/o externos.

Para el análisis de competitividad, utilizaremos los indices que se describen a conlinuación. Son indices que nos muestran una aproximación de la competitividad de la industria salvadorena. El análisis se realizará a nivel de sector, ramas y subramas. Además ulilizaremos algunos indicadores de tendencia que nos ayudarán a explicar de mejor manera el problema.

\section{a) Coeficiente de exportaciones}

Este indicador proporciona el porcentaje de la producción que se exporta, es decir, cuánlo de lo que produce una rama, subrama, sector o pais se destina al mercado externo. El cálculo de este coeficiente es diferente según el caso. Para el país, se realiza de la forma siguiente:

$$
C X=\frac{X}{P I B},
$$

donde $X$ corresponde a las exportaciones totales del pais y PIB es el produclo interno bruto de nuestra economía.

El coeficiente de las ramas y subramas de la industria se calculó

2. Véase, por ejemplo, Juan Carlos Del Bello (1990). 
lomando como base el valor bruto de la producelón (VBP), ya que éste incluye los insumos intermedios utilizados en cada rama y subrama. La tórmula sería como sigue:

$$
C X=\frac{X}{\text { VBP }}
$$

Para el caso del sector industrial en su conjunto, el coeficiente de exportaciones se eslimo como un promedio de los coeficientes de exportación de las ramas, ya que si se realizaba en base al VBP del sector, se duplicaba el valor de la producción realizada por el sector al sumarse insumos intermedios utilizados del mismo sector, y si utilizábamos la sumatoria del valor agregado del sector industria dejábamos por fuera los insumos intermedios utilizados de otros sectores y los insumos importados.

El análisis de este coeficiente se complementará con el indice de Orientación del Destino de la Producción (OP):

$$
O P=\frac{\operatorname{Var} . X}{\operatorname{Var} \cdot \operatorname{VBP}}
$$

donde Var.X es la variación de las exportaciones en un período y Var. VBP es la variación del VBP en ese mismo periodo.

Si el indicador es mayor que uno, los incrementos en la producción son en menor proporción que los de las exportaciones. Esto nos diria, entre otras cosas, la tendencia de la producción adicional a destinarse al inercado externo. Si el resultado es uno, significa que el incremento en la producción se traduce a exportaciones. Esto refleja una tendencia a exportar. Puede ser la ampliación en la producción traducida a exportaciones, o parte de la producción existente incremenlando sus exportaciones, o una combinación de ambas. Por último, si el índice es menor que uno, nos mostraria una tendencia a destinar la producción hacia el abastecimienlo del mercado interno. A nivel de pais, la tendencia se estima en relación al Producto Interno Bruto (PIB).

\section{b) Saldos normallzados de comercio}

Este indicador (Del Bello, 1990. p.12) loma como "proxy" de compelitividad el saldo oblenido entre las exportaciones e importaciones; se normaliza con el volumen lotal del comercio, permitiendo efectuar comparaciones entre ramas al margen de los valores absolutos del saldo. 
De esta forma, el coeficiente resultante oscilará entre -1 y 1 , siendo positivo cuando una actividad es superavitaria y negativo cuando la misma es deficitaria. La formula es la siguiente:

$$
S N C=\frac{X j-M j}{X m+M m}
$$

donde $X j$ son las exportaciones de la rama industrial $\mathrm{j}$ y Mj las importaciones de la rama industrial $\mathrm{j}$. Si el indicador es superior a cero y más próximo a la unidad, la actividad es más competitiva, y si es menor que cero y más próximo a -1, la actividad no es competitiva.

Como complemento al análisis, utilizaremos el indice de Desarrollo del Comercio Internacional (DCl):

$$
\mathrm{DCl}=\frac{\operatorname{Var} . \mathrm{X}}{\operatorname{Var} . \mathrm{M}},
$$

donde Var.X es la variación de las exportaciones en un período determinado y Var.M es la variación de las importaciones en ese mismo periodo.

Este nos indica nuestra tendencia en el intercambio comercial: si vamos hacia una eliminación, reducción o incremento de la dependencia del mercado internacional, y por ende a incrementar o reducir nuestra compelitividad. Si el indicador es mayor que uno significa una tendencia a exportar más de lo que requerimos de imporlaciones, y por consiguiente a disminuir nuestra dependencia y a ir incrementando nuestra competilividad. Si actualmente el saldo de la balanza comercial es negativo, significará una tendencia hacia la reducción de ese saldo. Si el indice es igual a uno, nos indica una lendencia al equilibrio en nuestro inlercambio. Podría decirnos que el ingreso adicional obtenido por exporlaciones se traduce en importaciones.

Si dicho indice es menor que uno, nos indica una tendencia a la dependencia de los productos exiranjeros; es decir, al dominio de las imporlaciones en nuestra demanda inlerna para suplir las necesidades de bienes y servicios y por ende a reducir cada vez más nuestra competilividad tanto nacional como internacional.

\section{c) Competitividad aparente}

El indicador de compelitividad aparente (Del Bello, 1990, p.13) inlenta estimar la competitividad utilizando como referencia la competitividad 
promedio de la industria local. De esta forma, si el coeficiente es mayor que la unidad, el grupo industrial analizado tendría una ventaja comparativa aparente en relación con la industria manufacturera nacional. Cuando es mayor que uno, este indicador nos rellejaria que la importancia relativa del comercio externo de la rama industrial es mucho más significativa en relación con la industria manufacturera.

$$
\begin{aligned}
& C A=\frac{\frac{X j}{M j}}{\frac{X m}{M m}} \times \frac{\frac{X j+M j}{P j}}{\frac{X m+M m}{P m}} \\
& C A=a \times b
\end{aligned}
$$

donde $\mathrm{Xj}_{\mathrm{j}} \mathrm{Mj}$ y $\mathrm{Pj}$ son, respeclivamente, exportaciones, importaciones y producción de la rama j; Xm, Mm y $\mathrm{Pm}$ corresponden a las mismas variables, referidas al total de la industria manufacturera.

Este indicador se compone de dos factores: $a$ y $b$. Si a es mayor que la unidad exisliria una competitividad aparente en la subrama " $j$ " en relación al conjunto de la producción industrial local; a su vez, b "corrige" este indicador moslrando la importancia relaliva -respecto al promedio industrial- del comercio externo de la rama en relación a la producción. De esta manera, una rama que muestre una competitividad por encima de la industria pero con una escasa aperlura exlema resultará menos competiliva que una en que ambos factores se reluercen.

\section{d) Coeficlente de penetración relatlva de importaclones}

Este indicador (Del Bello, 1990, p. 14) mide el impacto de las imporlaciones de una rama industrial, particular en el consumo aparente de esa rama con relación a el promedio de la industria manufacturera.

$$
P I=\frac{\frac{M j}{C A j}}{\frac{M m}{C A m}}
$$

donde Mj serian las importaciones de la rama industrial j; Mm las importaciones industriales; $\mathrm{CAj}$ el consumo aparente de la actividad industrial 
j; y CAm el consumo aparenle industrial. De esta forma, si el coeficiente es mayor que uno, la parte del mercado local de una rama industrial que se cubre con importaciones sería mucho mayor que la proporción de las importaciones industriales que abastecen el mercado nacional de la indusiria manufacturera; en tal sentido, dentro de la industria en su lotalidad, el impacto de las importaciones en esa rama es tan alto que podríamos decir, dependiendo de las especificaciones de ella, que su compelilividad en el mercado local es baja. $Y$ si, por el contrario, si es menor que uno, su competitividad en el mercado local es buena.

Este coeliciente se relaciona mucho con el siguiente indicador de tendencia:

Abastecimiento del Mercado Interno $=$ Demanda interna (AMI)

$$
\mathrm{AMI}=\frac{\operatorname{Var} \cdot \mathrm{M}}{\operatorname{Var} \cdot \mathrm{CA}}
$$

donde Var.M es la variación de las importaciones en un período determinado: y Var.CA, es la variación del consumo aparente en ese mismo periodo. Si el índice es mayor que uno, nos indicaría una tendencia a suplir la demanda inlerna con productos importados. Cuando el indicador sea igual a uno, puede decirse que ese incremento del CA está siendo suplido con importaciones. No obstante, podria ser también una sustitución por consumo ya existente en el mercado. Si el resultado es menor que la unidad, nos indicará que el incremenlo del consumo interno tiene una tendencia a suplirse con la producción inlerna y, por lo lanlo, exisliría una desaceleración en la incidencia de las importaciones en nueslro mercado interno.

Oro índice importante como complemento en este análisis será el siguiente:

Proporción de las Importaciones dentro del Consumo Aparente (CM).

$$
\mathrm{CM}=\frac{\mathrm{M}}{\mathrm{CA}}
$$

que nos da la proporción del consumo aparente que se cubre con importaciones. 


\section{La capacldad compelltiva del sector Industrlal en El Salvador}

\subsection{Aspeclos metodologicos}

Para realizar los cálculos sobre los indicadores de competitividad, hemos agrupado las distintas actividades industriales de acuerdo con la Clasilicación Internacional Industrial Unilorme (CIIU). La elección de esla clasificación se debe a dos razones fundamentales. Primero, es la que se utiliza a nivel mundial; y, segundo, la información referente a la producción se registra bajo esle sistema. De esta manera, los datos relativos al secior industria manulacturera se presentan a nivel de dos y tres dígilos según CIIU, es decir, por ramas y subramas industriales. Además, se realiza una agrupación según calegoria de destino: bienes de consumo no duradero, bienes intermedios y bienes consumo duradero y capital. En los cuadros 1 y 2 se delallan estas clasilicaciones.

Cuadro 1

Claslificaclón de acuerdo a codigo CIUU por rama

\begin{tabular}{|cl|}
\hline Código & \multicolumn{1}{c|}{ Rama } \\
\hline 31 & Alimentos, bebidas y tabaco \\
32 & Textiles y cuero \\
33 & Madera y sus productos \\
34 & Papel, imprenla y editoriales \\
35 & Industrias quimicas \\
36 & Industrias metálicas básicas \\
37 & Minerales no metálicos \\
38 & Productos metálicos, maquinaria y equipo] \\
39 & Otras industriasl \\
\hline
\end{tabular}

Fuente: CEPAL

Los dalos relalivos al valor agregado y valor brulo de la producción por ramas y subramas fueron proporcionados por el Departamento de Cuentas Nacionales del Banco Central de Reserva.

Los datos relerentes a las exportaciones e importaciones para los mismos ahos fueron facilitados por el Ministerio de Economía.

Los datos se derivan de las pólizas de exportación e importación que emiten las respectivas aduanas. La iniormación eslaba clasificada según la Nomenclatura Arancelaria Uniforme Centroamericana (NAUCA), orde- 
Cuadro 2

Clasilicación por categorla de destino y de acuerdo a codigo CllU por subrama

\begin{tabular}{|ll|}
\hline Código & \multicolumn{1}{c|}{ Bienes/Subramas } \\
\hline A. & Bienes de consumo no duradero \\
311 & Alimentos \\
313 & Bebidas \\
314 & Tabaco \\
322 & Prendas de vestir \\
324 & Calzado \\
342 & Imprenta \\
361 & Barro y porcelana \\
390 & Diversos \\
& \\
B. Blenes Intermedios \\
321 & Textiles \\
323 & Cueros \\
331 & Madera cafia y corcho \\
341 & Papel y carlon \\
351 & Sustancias quínicas \\
352 & Produclos químicos \\
353 & Refinerias de petróleo \\
354 & Deriv. petróleo y carbo \\
355 & Caucho \\
362 & Vidrio y sus productos \\
369 & Minerales no melálicos \\
371 & Hierro y acero \\
372 & Melales no lerrosos \\
381 & Produclos metálicos \\
& \\
C. Blenes de consumo duradero y capltal \\
332 & Muebles \\
382 & Maquinaria no eléct. \\
383 & Maquinaria y apar. eléct. \\
384 & Equipo de lransporte \\
385 & Equipo cienlílico \\
\hline
\end{tabular}

Fuenle: CEPAL. 
nada por código de país, según tipo de producto, precios CIF y FOB y volumen. En tal sentido, hubo que hacer una conversión de la información de NAUCA a CIIU; para ello generamos una tabla de conversión a partir de dos tablas que nos lueron proporcionadas, una por el Ministerio de Economía y otra -más actualizada, pero en algunos casos menos desagregada que la primera - por el Departamento de Inlormálica del Banco Central. Con esla última realizamos la primera conversión. Luego a los códigos que no se les encontró su equivalente se les asignó, revisando en lorma manual la primera tabla y la NAUCA, generándose la nueva labla que luego se procesó para realizar la conversión total. Ya realizada esta parte se procedió a ordenar loda la información de acuerdo a las necesidades del trabajo. Cabe aclarar que los datos sobre exportaciones e importaciones se ordenaron a nivel de dos, tres y cuatro digitos pero que por limilantes en la información de la producción, se utilizó hasta el nivel de tres dígitos.

La información de exportaciones e importaciones, también lue ajustada para tomar en cuenta modificaciones en el tipo de cambio. Esto porque los valores de estas variables estaban al cambio del $₫ 5$ por $\$ 1$, lo que signiticó convertirla para los ańos 1989 y 1990 al cambio de $₫ 5.6$ por $\$ 1$ y de $\$ 7.6$ por $\$ 1$, respectivamente.

Otro dato utilizado en el análisis fue el referenle al Consumo Intermedio total, la parte importada y nacional. Para su estimación se recurrió a la matriz insumo producto de 1978, utilizando dentro de ella los coeficientes lécnicos de insumos intermedios tolales e importados.

\subsection{Competitividad en el sector Industrlal}

\section{Coeficiente de exportaciones y orlentación de la producción}

El nivel y comportamiento de nuestras exportaciones, asi como el deslino de nuestra producción al mercado interno, tanto de la economía en su conjunto como del sector industrial, podemos evaluarlo a través de dos indices: el coeficiente de exportaciones y el indice orientación del deslino de la producción.

El cuadro 3 , nos muestra el coeficiente de exportaciones para toda la economía durante el período 1985-1990.

Como se puede apreciar, 1986 fue el afio en que nuestro país ha mostrado un nivel bastante superior al promedio del período que fue del $12.4 \%$; siluación que no es producto de incrementos significalivos en el volumen de exporlaciones, sino más bien a variaciones en los precios internacionales, principalmente de los precios del café, que durante 1986 alcanzaron su mejor nivel durante la década. 


$\begin{gathered}\text { Cuadro 3 } \\
\text { Coeflclente de exportaciones } \\
\text { 1985-1990 } \\
(\%)\end{gathered}$
\begin{tabular}{|cc|}
\hline Anos & Coeficiente \\
\hline 1985 & 12.1 \\
1986 & 19.1 \\
1987 & 12.8 \\
1988 & 11.1 \\
1989 & 8.6 \\
1990 & 10.7 \\
\hline $1985 / 90$ & 12.4 \\
$1988 / 90$ & 10.2 \\
\hline
\end{tabular}

Fuente: Morán y Contreras (1992), Anexo 10.

A partir de 1987 a 1989 puede verse una tendencia a la disminución de nuestras exporlaciones, lendencia que puede apreciarse mejor en el cuadro siguiente, donde se muestra el índice sobre orientación del destino de la producción, que evalúa las variaciones de las exportaciones y el producto durante el mismo período.

\section{Cuadro 4}

Orientación del destino de la producción 1985-1990

\begin{tabular}{|c|c|}
\hline Años & Coeficiente \\
\hline 1986 & 3.1 \\
1987 & $(1.3)$ \\
1988 & 0.2 \\
1989 & $(0.5)$ \\
1990 & 2.1 \\
\hline
\end{tabular}

Fuenle: Morán y Contreras (1992), Anexo 10.

Efectivamente, entre 1987 y 1989 , el indice resultante es menor que 
uno y además en dos anos negativo, lo cual denota una tendencia clara a la disminución de nuestras exportaciones. Sin embargo, 1990 presenta una tendencia nuevamente hacia el incremento de las exportaciones (Cuadros 3 y 4); esto a pesar de las disminuciones en los precios del café. La lendencia responde sobre todo a un incremento en el volumen de las exportaciones, tanto del sector agropecuario como del sector industrial, que ya desde el año 1989 muestra una recuperación en sus niveles de exportación. Esto puede haber respondido a la devaluación de la moneda.

En lo que se refiere al seclor industrial, el cuadro 5 nos presenta el coeficiente de exportaciones para el periodo 1988-90. Podemos ver que para este período el coeficienle promedio es del $17.7 \%$, significativamente mayor al de la economia en su lotalidad. Fue en 1990 en que mejor resultado se observó en este seclor, donde el coeficiente lue el $\mathbf{2 0 . 8 \%}$, como resultado del crecimiento en el volumen de exportaciones y en el tipo de cambio.

La exporlaciones del sector industrial presentan una lendencia hacia el crecimiento para las dislintas ramas y subramas, a excepción de la rama minerales no metálicos (CIIU 36), como se aprecia en los cuadros 5 y 6 .

\section{Cuadro 5}

Coeficiente de exportaclones según ramas Industrlales

(\%)

\begin{tabular}{|c|c|c|c|}
\hline $\begin{array}{l}\text { Código } \\
\text { Rama }\end{array}$ & 1988 & 1989 & 1990 \\
\hline 31 & 5.5 & 4.3 & 5.4 \\
\hline 32 & 11.3 & 12.5 & 18.1 \\
\hline 33 & 1.5 & 1.9 & 2.9 \\
\hline 34 & 33.3 & 34.9 & 41.5 \\
\hline 35 & 8.2 & 10.2 & 12.6 \\
\hline 36 & 0.5 & 1.8 & 1.3 \\
\hline 37 & 24.8 & 35.7 & 42.1 \\
\hline 38 & 8.3 & 12.0 & 19.0 \\
\hline 39 & 44.4 & 38.0 & 44.7 \\
\hline $\begin{array}{l}\text { Promed } \\
\text { Indusl. }\end{array}$ & \multicolumn{2}{|c|}{ Promedio } & 20.8 \\
\hline
\end{tabular}

Fuente: Morán y Contreras (1992).

Anexo 12. 
Cuadro 6

Coeflclentes de exportaciones según categorias de destino

(\%)

\begin{tabular}{|c|c|c|c|c|}
\hline & Oncepto & & & \\
\hline Código & Bienes/Ramas & 1988 & 1989 & 1990 \\
\hline A. Blen & es de consumo no duraderos & 6.0 & 5.4 & 6.9 \\
\hline 311 & Alimentos & 5.9 & 4.5 & 5.7 \\
\hline 313 & Bebidas & 4.9 & 4.3 & 4.9 \\
\hline 314 & Tabaco & 0.5 & 0.2 & 0.4 \\
\hline 322 & Prendas de veslir & 2.9 & 5.5 & 9.7 \\
\hline 324 & Calzado & 10.8 & 12.9 & 18.6 \\
\hline 342 & Imprenta & 7.0 & 6.4 & 6.8 \\
\hline 356 & Produclos de plásticos & 10.6 & 12.4 & 15.4 \\
\hline 361 & Barro y porcelana & 0.1 & 0.2 & 4.9 \\
\hline 390 & Diversos & 44.4 & 38.0 & 44.7 \\
\hline B. Blen & es Intermedios & 11.7 & 13.9 & 18.1 \\
\hline 321 & Textiles & 15.9 & 16.1 & 22.7 \\
\hline 323 & Cueros & 4.1 & 7.2 & 9.8 \\
\hline 331 & Madera caña y corcho & 1.2 & 1.6 & 4.1 \\
\hline 341 & Papel y cartón & 56.5 & 62.6 & 74.5 \\
\hline 351 & Sustancias químicas & 16.1 & 17.1 & 19.8 \\
\hline 352 & Productos quírnicos & 11.6 & 13.5 & 16.7 \\
\hline 353 & Relinerias de Petróleo & 2.2 & 4.3 & 5.7 \\
\hline 354 & Derivados de peiróleo y carbón & 0.3 & 0.6 & 0.8 \\
\hline 355 & Caucho & 0.3 & 0.2 & 0.5 \\
\hline 362 & Vidrio y sus productos & 2.4 & 2.6 & 1.7 \\
\hline 369 & Minerales no melálicos & 0.5 & 1.9 & 1.0 \\
\hline 371 & Hiero y acero & 2.8 & 5.2 & 12.7 \\
\hline 372 & Melales no ferrosos & 67.3 & 91.1 & 96.4 \\
\hline 381 & Productos metálicos & 12.1 & 17.4 & 25.0 \\
\hline C. Blen & es de consumo duradero y capital & 5.8 & 8.3 & 13.4 \\
\hline 332 & Muebles & 1.8 & 2.3 & 1.6 \\
\hline 382 & Maquinaria no eléctrica & 13.4 & 18.3 & 19.2 \\
\hline 383 & Maquinaria y aparatos eléctricos & 5.5 & 10.9 & 22.4 \\
\hline 384 & Equipo de transporte & 9.7 & 7.7 & 9.2 \\
\hline 385 & Equipo cientifico & 2.3 & 2.1 & 5.2 \\
\hline Tota & I Industrla & 15.3 & 16.8 & 20.0 \\
\hline
\end{tabular}

Fuente: Morán y Contreras (1992), Anexo 15. 
Algunas ramas presentan coeficientes de exportación bastanle altos, como son las ramas de Papel, Imprenta y Editoriales (CIIU 34) y Melálicas Básicas (CIIU 37), con coeficientes del $41.5 \%$ y $42.2 \%$ respectivamente, para el año de 1990. Les siguen las ramas de Produclos Metálicos, Maquinaria y Equipo (CIIU 38), Textiles y Cuero (CIIU 32) e IndusIrias Químicas (CIIU 35), con coelicienles del $19.0 \%, 18.1 \%$ y $12.6 \%$, respeclivamente.

Al bajar a un mayor detalle (cuadro 22), son las subramas de Metales no Ferrosos (CIIU 372) y Papel y Cartón (CIIU 341) las que tienen mayores coeficientes de exportación para 1990, con indices de $96.4 \%$ y $74.4 \%$ respectivamenle, y por consiguiente las que inciden en que las ramas 34 y 37 muestren allos índices de exportación. Les siguen las subramas de Productos Metálicos (CIIU 381), Textiles (CIIU 321), Maquinaria y Aparatos Eléctricos (CIIU 383 ) y las Sustancias Químicas con coeficientes del $25 \%, 22.7 \%, 22.4 \%$ y $19.8 \%$, respeclivamenle.

De acuerdo a la agrupación por categoría de destino, son los Bienes Inlermedios los que alcanzan un mayor nivel de exporlaciones de su producción con un $18.1 \%$; le siguen los Bienes Duraderos con un coeficiente del $13.4 \%$, y por último tenemos los Bienes de Consumo no Duradero con un indice del $6.9 \%$, muy por debajo del coeficiente de exporlaciones del seclor y del país. Obsérvese el coeficiente de exporlaciones particularmente bajo de la rama Alimentos, Bebidas y Tabaco -la primera en importancia en términos de su contribución al PIB industrial一. que denola una producción orientada al consumo interno. El índice de orientación del destino de la producción deja mejor manifiesto de esta siluación, como lo muesiran los cuadros 7 y 8 .

\section{Cuadro 7}

Orientaclón del dsdtino de la producción sector Industrial

\begin{tabular}{|ccc|}
\hline $\begin{array}{c}\text { Código } \\
\text { Rama }\end{array}$ & 1989 & 1990 \\
\hline 31 & 0.0 & 2.1 \\
32 & 1.7 & 4.2 \\
33 & 2.3 & 3.6 \\
34 & 1.2 & 1.8 \\
35 & 3.1 & 2.9 \\
36 & 25.4 & $(0.3)$ \\
37 & $(16.3)$ & 1.8 \\
38 & $(21.1)$ & 182.3 \\
39 & 0.2 & 2.2 \\
\hline
\end{tabular}

Fuente: Morán y Contreras (1992),

Anexo 12. 
Cuadro 8

Orlentaclón del destino de la producción

según calegorla de destino

\begin{tabular}{|c|c|c|c|}
\hline \multicolumn{2}{|c|}{ Conceplo } & \multirow[b]{2}{*}{1989} & \multirow[b]{2}{*}{1990} \\
\hline Código & Bienes/Ramas & & \\
\hline \multicolumn{2}{|c|}{ A. Blenes de consumo no duraderos } & 0.5 & 2.3 \\
\hline 311 & Alimentos & 0.0 & 2.2 \\
\hline 313 & Bebidas & 0.4 & 1.5 \\
\hline 314 & Tabaco & $(3.0)$ & 4.4 \\
\hline 322 & Prendas de veslir & 6.8 & 6.2 \\
\hline 324 & Calzado & 2.1 & 6.1 \\
\hline 342 & Imprenta & 0.7 & 1.3 \\
\hline 356 & Productos de pláslicos & 2.0 & 3.3 \\
\hline 361 & Barro y porcelana & 9.4 & 187.8 \\
\hline 390 & Diversos & 0.2 & 2.2 \\
\hline \multicolumn{2}{|c|}{ B. Blenes Intermedlos } & 2.7 & 3.0 \\
\hline 321 & Textiles & 1.1 & 3.9 \\
\hline 323 & Cueros & 5.4 & 2.8 \\
\hline 331 & Madera caña y corcho & 2.4 & 9.4 \\
\hline 341 & Papel y carlón & 1.6 & 1.8 \\
\hline 351 & Sustancias químicas & 1.5 & 1.9 \\
\hline 352 & Productos químicos & 2.0 & 3.2 \\
\hline 353 & Refinerías de Pelróleo & 86.8 & 3.2 \\
\hline 354 & Derivados de petróleo y carbón & $(52.4)$ & 12.5 \\
\hline 355 & Caucho & (1.3) & 12.3 \\
\hline 362 & Vidrio y sus produclos & 1.3 & $(0.6)$ \\
\hline 369 & Minerales no metálicos & 39.6 & (1.1) \\
\hline 371 & Hiero y acero & (16.9) & 6.9 \\
\hline 372 & Melales no ferrosos & 24.7 & 1.3 \\
\hline 381 & Productos melálicos & (4.7) & 25.5 \\
\hline \multicolumn{2}{|c|}{ C. Bienes de consumo duradero y capital } & 10.1 & 19.4 \\
\hline 332 & Muebles & 2.1 & (0.6) \\
\hline 382 & Maquinaria no eléctrica & 4.0 & 1.4 \\
\hline 383 & Maquinaria y aparatos eléctricos & (4.9) & 11.1 \\
\hline 384 & Equipo de transporte & 1.8 & 2.7 \\
\hline 385 & Equipo cientílico & 0.0 & (3.7) \\
\hline
\end{tabular}

Fuente: Morán y Contreras (1992), Anexo 16. 
En 1990, a nivel de ramas, a excepción de Minerales no Metálicos (CIIU 36), todos los índices superaron la unidad y fueron positivos, lo que denota una lendencia a la exportación más que ventas al mercado interno. Se destaca con esta tendencia la rama de Productos Metálicos, Maquinaria y Equipo, que prácticamenle con la misma producción (incremento $0.32 \%$ ) para 1990 , ha dado el cambio hacia la exportación, resultado en gran medida del incremento de las exportaciones $(88.9 \%$ ) en la sub-rama de Equipo Científico en el contexlo de una disminución en su producción. Además, está el aumento de la exportaciones de la subrama de Maquinaria y Aparalos Eléctricos (129.3\%).

Caso curioso es el de la rama Minerales no Metálicos, que no obstante presenta una lendencia hacia la no exportación, producto de la disminución en las exportaciones de las sub-ramas Vidrio y sus produclos (CIIU 362) y otros Minerales no Melálicos (CIIU 369); la sub-rama Barro y Porcelana (CIIU 361) es la que presenla el mayor indice de Orientación del Destino de la Producción, debido al incremento sustancial de sus exportaciones en relación al ano anterior.

\section{Saldos normallzados de comerclo}

En general nuestro pais y el seclor industrial en particular, presenta indicadores que nos reflejan una aclividad deficilaria para los tres ańos analizados, que se observa en el cuadro 9. El crecimiento proporcional similar que las exportaciones y las importaciones han experimentado en este período tiende a perpetuar ese desequilibrio.

Según rama industrial, es la de Textiles y Cuero (CIIU 32) la única que presenta un panorama alentador con coeficientes positivos, aunque no cercanos a la unidad, de $0.3,0.3$ y 0.2 para los anos 1988 a 1990 . lo que significa que su actividad es superavitaria en un margen muy escaso. El resto de ramas presentan indicadores negativos denotando una actividad delicitaria. Este balance positivo en la actividad comercial denota que tiene alguna compelitividad, pero un poco baja, to que indica que la oferta exportable no es tan superior a la demanda por imporlaciones de este grupo industrial, además que para el ano 1990 ha sufrido una disminución de este coeficiente (ver cuadro 9). Esta siluación se combina con la disminución en la tendencia de manlener ese superávit comercial, ya que para 1990 las importaciones de esta rama se incrementaron en mayor proporción que sus exportaciones, según se puede apreciar en el cuadro 10.

Se observa, además, que el reslo de ramas, a excepción de Industrias Químicas (CIIU 35), Minerales no Metálicos (CIIU 36) y Otras Industrias (CIIU 39) han mostrado para 1990 una tendencia a incrementar 


\section{Cuadro 9}

Saldos normalizados del comerclo según ramas Industrlales

\begin{tabular}{|lccc|}
\hline $\begin{array}{l}\text { Código } \\
\text { Rama }\end{array}$ & 1988 & 1989 & 1990 \\
\hline 31 & $(0.3)$ & $(0.3)$ & $(0.3)$ \\
32 & 0.3 & 0.3 & 0.2 \\
33 & $(0.8)$ & $(0.7)$ & $(0.7)$ \\
34 & $(0.3)$ & $(0.3)$ & $(0.2)$ \\
35 & $(0.7)$ & $(0.7)$ & $(0.8)$ \\
36 & $(0.9)$ & $(0.8)$ & $(0.9)$ \\
37 & $(0.6)$ & $(0.6)$ & $(0.6)$ \\
38 & $(0.9)$ & $(0.9)$ & $(0.8)$ \\
39 & $(0.2)$ & $(0.3)$ & $(0.4)$ \\
\hline Tolal & & & \\
Indust. & $(0.6)$ & $(0.6)$ & $(0.6)$ \\
Pais & $(0.2)$ & $(0.3)$ & $(0.3)$ \\
\hline
\end{tabular}

Fuente: Morán y Contreras (1992), Anexo 12.

\section{Cuadro 10}

Indice de tendencla desarrollo del comercio Internacional

\begin{tabular}{|lrc|}
\hline $\begin{array}{l}\text { Código } \\
\text { Rama }\end{array}$ & 1989 & 1990 \\
\hline 31 & 0.1 & 1.1 \\
32 & 1.3 & 0.7 \\
33 & 3.3 & 2.5 \\
34 & 1.5 & 1.8 \\
35 & 2.1 & 0.4 \\
36 & 16.5 & $(0.3)$ \\
37 & 0.6 & 2.3 \\
38 & 1.4 & 3.1 \\
39 & 0.2 & 0.6 \\
\hline Industria & 1.0 & 1.0 \\
Pais & $(0.3)$ & 1.0 \\
\hline
\end{tabular}

Fuente: Morán y Contreras (1992), Anexo 12. 
más sus exportaciones que sus importaciones. No obstante, eslo no ha cambiado aún su desventaja compelitiva Irente a las importaciones de eslos produclos, como puede verse en el cuadro 9.

Dentro de las subramas, las de la rama de Textiles con excepción de la subrama Cueros, son las que mantienen coeficientes positivos pero con el mismo comportamiento que la rama en su totalidad.

Son las subramas de Muebles y Bebidas, y sobre lodo Muebles, las que presentan siluaciones más importanles (ver cuadro 11). Las primeras, presentan coeficientes positivos de 0.5 y 0.4 , respectivamente, a partir de 1989 , lo que denola una mejora en su oferta exportable si lo vemos en relación con el afio 1988 en que su coeficiente era negalivo, significando una actividad deficilaria muy contraria a la de los afios siguientes, ubicándola como una actividad que tiene una competitividad mejor que el resto de subramas con indices positivos.

La subrama de Bebidas ha tenido una decadencia en sus coeficientes, luego que en 1988 era del 0.6, para 1990 solo es de 0.3.

A pesar de la situación generalizada hacia coeficientes negativos, y por consiguiente a la baja o casi nula competitividad en la mayoria de las subramas, existen otras como, por ejemplo Hierro y Acero, y Barro y Porcelana, que presentan una tendencia hacia la disminución de esa situación deficitaria y poco competititiva (ver cuadro 12).

\section{Competllividad aparente}

Con este indicador, lo que se intenta evaluar es la ventaja comparativa aparente de la industria, ramas y subramas en relación con los olros sectores de la economia y dentro del mismo sector, asi como su imporlancia relativa del comercio externo en relación con la industria.

Las ramas industriales que muestran una ventaja comparativa dentro de la industria total son Industrias Diversas (CIIU 39); Papel, Imprenta y Editoriales (CIIU 34); Melálicas Básicas (CIIU 37); Texliles y Cuero (CIIU 32) y Productos Melálicos, Maquinaria y Equipo (CIIU 38). Esto puede apreciarse en el cuadro 13.

Estas mismas ramas, al presentar indices mayores que la unidad, to que reflejan es una importancia relativa en el comercio externo dentro de la industria en su totalidad.

Las ramas CIIU 34, 37 y 39, son las que reflejan además de una compelitividad por encima de la del sector, una apertura exlerna también mayor que el resto (faclor $b$ ) -a excepción de la rama CIIU $38-$, lo que las ubica como las de mejor competitividad dentro de la industria 
Cuadro 11

Saldos normalizados del comercio según categorias de deslino

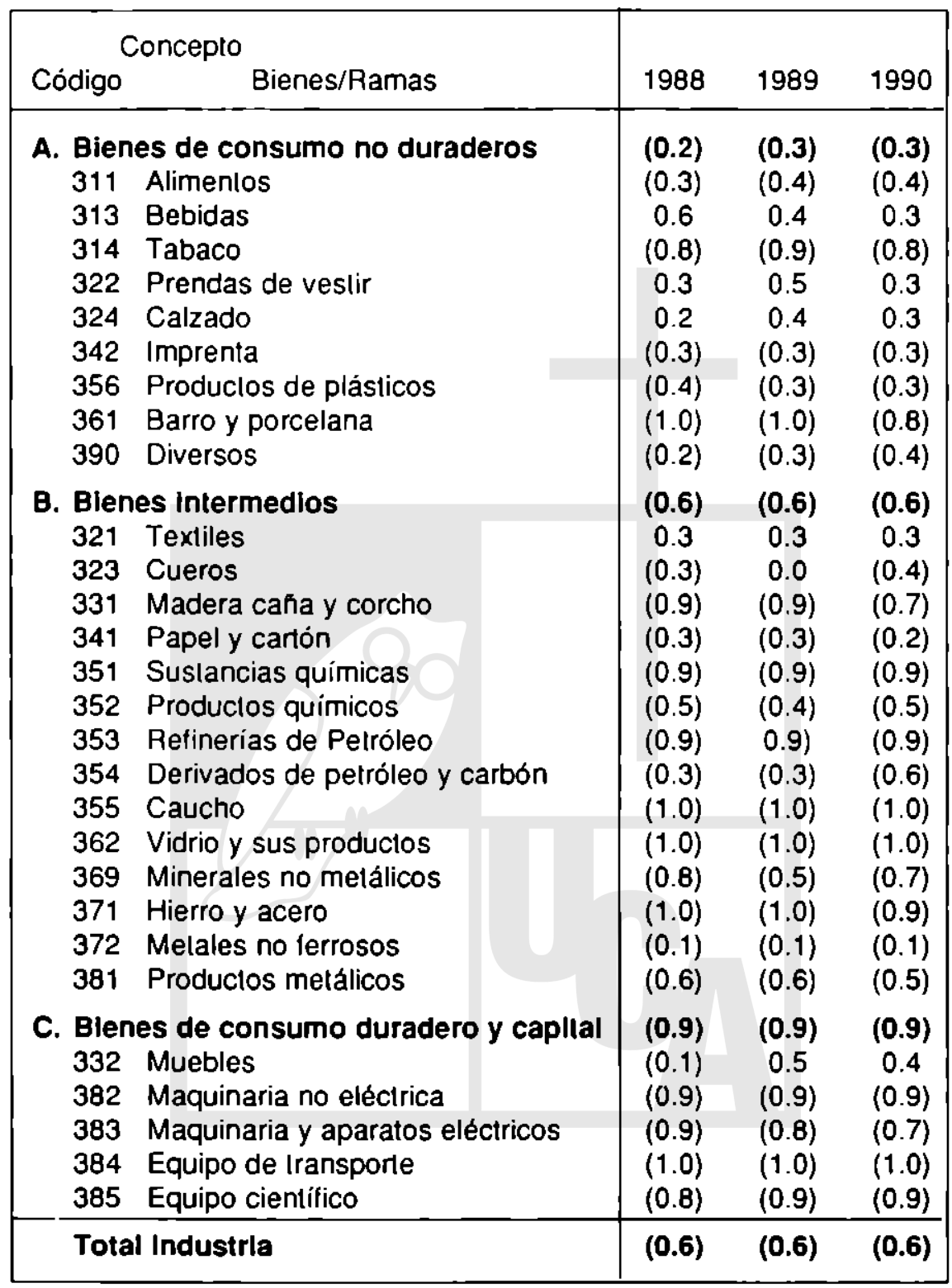

Fuente: Morán y Conlreras (1992), Anexo 15 
Cuadro 12

Desarrollo del comercio Internacional según categoría de destino

\begin{tabular}{|c|c|c|c|}
\hline \multicolumn{2}{|c|}{ Conceplo } & \multirow[b]{2}{*}{1989} & \multirow[b]{2}{*}{1990} \\
\hline Código & Bienes/Ramas & & \\
\hline \multicolumn{2}{|c|}{ A. Blenes de consumo no duraderos } & 07. & 1.1 \\
\hline 311 & Alimentos & 0.0 & 1.2 \\
\hline 313 & Bebidas & 0.1 & 0.5 \\
\hline 314 & Tabaco & $(6.2)$ & 4.9 \\
\hline 322 & Prendas de vestir & 2.6 & 0.5 \\
\hline 324 & Calzado & 5.2 & 0.7 \\
\hline 342 & Imprenta & 0.8 & 0.9 \\
\hline 356 & Productos de plásticos & 2.8 & 1.1 \\
\hline 361 & Barro y porcelana & 10.9 & 48.8 \\
\hline 390 & Diversos & 0.2 & 0.6 \\
\hline \multicolumn{2}{|c|}{ B. Blenes intermedios } & 1.3 & 0.7 \\
\hline 321 & Textiles & 0.7 & 0.9 \\
\hline 323 & Cueros & 7.5 & 0.3 \\
\hline 331 & Madera caña y corcho & 2.6 & 6.5 \\
\hline 341 & Papel y carlón & 1.6 & 1.9 \\
\hline 351 & Suslancias quimicas & 0.7 & 0.7 \\
\hline 352 & Produclos quimicos & 1.8 & 0.8 \\
\hline 353 & Refinerías de Petróleo & 8.3 & 0.3 \\
\hline 354 & Derivados de pelróleo y carbón & 1.1 & 0.1 \\
\hline 355 & Caucho & $(4.0)$ & 4.0 \\
\hline 362 & Vidrio y sus productos & 3.5 & $(0.9)$ \\
\hline 369 & Minerales no metálicos & 12.6 & $(0.8)$ \\
\hline 371 & Hierro y acero & 1.0 & 10.6 \\
\hline 372 & Metales no lerrosos & 0.7 & 1.2 \\
\hline 381 & Productos metálicos & 1.0 & 3.0 \\
\hline \multicolumn{2}{|c|}{ C. Bienes de consumo duradero y capital } & 1.7 & 3.4 \\
\hline 332 & Muebles & $(1.9)$ & 6.9 \\
\hline 382 & Maquinaria no eléctrica & 2.3 & 1.8 \\
\hline 383 & Maquinaria y aparalos eléctricos & 1.9 & 7.5 \\
\hline 384 & Equipo de transporte & $(0.5)$ & 4.4 \\
\hline 385 & Equipo científico & 0.0 & 0.6 \\
\hline
\end{tabular}

Fuente: Morán y Contreras (1992), Anexo 15 
Cuadro 13

Competitlvidad aparente según ramas ndustrlales

\begin{tabular}{|l|ccc|ccc|ccc|}
\hline Cod. & \multicolumn{3}{|c|}{1988} & \multicolumn{3}{c|}{1989} & \multicolumn{3}{c|}{1990} \\
Rama & $\mathrm{A}$ & $\mathrm{B}$ & $\mathrm{A}^{*} \mathrm{~B}$ & $\mathrm{~A}$ & $\mathrm{~B}$ & $\mathrm{~A}^{*} \mathrm{~B}$ & $\mathrm{~A}$ & $\mathrm{~B}$ & $\mathrm{~A}^{*} \mathrm{~B}$ \\
\hline 31 & 2.2 & 0.4 & 0.8 & 1.8 & 0.3 & 0.6 & 1.9 & 0.3 & 0.6 \\
32 & 6.6 & 0.5 & 3.0 & 6.9 & 0.5 & 3.2 & 5.9 & 0.6 & 3.3 \\
33 & 0.4 & 0.4 & 0.2 & 0.6 & 0.4 & 0.2 & 0.8 & 0.3 & 03 \\
34 & 1.9 & 2.5 & 4.7 & 2.0 & 2.4 & 4.8 & 2.4 & 2.0 & 4.8 \\
35 & 0.6 & 1.6 & 0.9 & 0.7 & 1.6 & 1.1 & 0.5 & 2.1 & 1.0 \\
36 & 0.1 & 0.5 & 0.1 & 0.4 & 0.5 & 0.2 & 0.3 & 0.4 & 0.1 \\
37 & 1.0 & 3.0 & 3.0 & 0.8 & 4.8 & 3.9 & 1.0 & 3.7 & 3.8 \\
38 & 0.3 & 3.2 & 0.8 & 0.3 & 4.1 & 1.2 & 0.4 & 3.9 & 1.5 \\
39 & 2.4 & 2.9 & 6.9 & 2.0 & 2.6 & 5.2 & 1.7 & 2.7 & 4.6 \\
\hline Ind. & 0.4 & 2.1 & 0.8 & 0.6 & 2.3 & 1.3 & 0.6 & 2.4 & 1.3 \\
\hline
\end{tabular}

Fuente: Morán y Contreras (1992), Anexo 12.

local hacia el comercio externo. Sin embargo, es de hacer notar que la rama CIIU 39 ha ido perdiendo su imporlancia a Iravés del periodo analizado, debido a la pérdida de compelitividad que ha sufrido este grupo industrial en relación al conjunto de la producción industrial local (factor a), ya que la importancia relaliva del comercio externo de ésta se ha mantenido relativamente conslante en relación con la industria manufacturera.

La rama CIIU 34 ha manlenido un coeficiente más o menos constante durante los Ires anios, aunque contrario a la anterior su compelitividad ha ido aumentado, pero su apertura externa se ha deleriorado, lo que en alguna medida ha influido para su disminución en el coeficiente para 1990. Deniro de esta rama, la subrama Papel y Cartón (CIIU 34) es la que contribuye al resultado oblenido (Cuadro 14), la cual mantiene una apertura exlerna descendenle, pero con un incremento en su importancia a través del periodo, incrementando su indiç de competitividad aparente.

La rama CIIU 37 en 1989 representó una mejora en su coeliciente debido al incremento en su participación dentro del comercio externo de su producción lo que signiticó una mayor apertura externa. Para 1990 esta apertura disminuyó, pero su competitividad relativa dentro del sector se incrementó. De ahí que el coeficiente en su totalidad no sutrió un deterioro mayor. La subrama de Metales No Ferrosos es la que deniro 
de esta rama tiene el mayor indice de compelilividad, y además el mayor de todas las subramas (ver cuadro 14).

La rama de Textiles y Cuero, a pesar de tener una competitividad relativa superior al resto de las ramas dentro del lolal de la industria, tiene una apertura externa tan baja (promedio de 0.33), que la hace no ubicarse denlro de las ramas más competitivas. No obstante, es imporlanle destacar que su índice está por arriba de la unidad y ha mostrado una ascendencia entre el período 1988 y 1990, pasando de 3.0 a 3.3, producto de una lendencia hacia la apertura externa y no de importancia competiliva dentro del sector, ya que esta ha descendido para 1990. En estos resultados, las ramas de Textiles, Prendas de Vestir y Calzado son las de mayor imporlancia dentro del sector, lo que le signilica ventajas comparativas (véase el cuadro 14); y las tres presentan indices ascendenles, las últimas dos como resultado de una mejora en su imporlancia deniro del secior, y la primera, debido a un aumento en su apertura externa, aunque esta dista de ser un resullado arriba de la unidad. Pero esta situación es resultado del bajo nivel de importaciones que se realizan en este sector.

Contrario a la rama anterior, la rama de Productos Metálicos, Maquinaria y Equipo (CIIU 38) tiene una importancia compelitiva dentro del sector tan baja que a pesar de tener un indice de apertura externa bastante alto - superior al resto de las ramas - no le ha permitido un resullado de competitividad aparente muy alto; sin embargo, para 1989 y 1990 éste ha eslado arriba de la unidad y con una tendencia al incremento de la competitividad aparente.

Todas las subramas que componen esta actividad, a excepción de equipo científico, contribuyen a la siluación de esta rama, pero principalmente la subrama de Equipo de Transporte, la cual posee un indice de apertura externa bastante elevado debido al alto porcentaje de importaciones, ya que su imporlancia relativa de competitividad es sumamenle reducida. No obstante, esta situación, refleja el nivel competitivo de esta rama dentro del comercio internacional (ojo con el porcentaje importado dentro de las ramas, ya que será más significativo un coeficiente de competilividad arriba de la unidad donde el lactor a sea mayor que el factor "b" puesto que este último toma en consideración el comercio externo total $(x \mathrm{~m})$, y si la influencia de $\mathrm{m}$ es bastante alto entonces el coeliciente total estará influenciado por ese elemento).

La rama Alimentos, Bebidas y Tabaco (CIIU 31), aunque tiene una competitividad superior a otras y con un índice arriba de la unidad, su apertura externa es tan baja que la competilividad aparente dentro del mercado internacional no es alta. Esta siluación se refuerza al tener este 
Cuadro 14

Competitivldad aparente según categorla de destino

\begin{tabular}{|c|c|c|c|c|c|c|c|c|c|}
\hline \multirow{2}{*}{$\begin{array}{l}\text { Cod.. } \\
\text { Rama }\end{array}$} & \multicolumn{3}{|c|}{1988} & \multicolumn{3}{|c|}{1989} & \multicolumn{3}{|c|}{1990} \\
\hline & A & B & $A^{*} B$ & A & B & $A^{*} B$ & A & B & $A^{*} B$ \\
\hline BCND & 2.3 & 0.4 & 0.9 & 2.2 & 0.4 & 0.8 & 2.2 & 0.3 & 0.8 \\
\hline 311 & 2.0 & 0.4 & 0.9 & 1.7 & 0.4 & 0.6 & 1.8 & 0.3 & 0.6 \\
\hline 313 & 14.0 & 0.2 & 2.2 & 8.9 & 0.2 & 1.3 & 6.5 & 0.1 & 0.9 \\
\hline 314 & 0.5 & 0.1 & 0.1 & 0.2 & 0.1 & 0.0 & 0.4 & 0.1 & 0.0 \\
\hline 322 & 6.4 & 0.1 & 0.8 & 9.7 & 0.2 & 1.8 & 6.7 & 0.3 & 1.9 \\
\hline 324 & 5.9 & 0.5 & 2.7 & 7.8 & 0.5 & 3.6 & 6.5 & 0.6 & 3.6 \\
\hline 342 & 2.1 & 0.5 & 1.0 & 2.0 & 0.4 & 0.9 & 1.9 & 0.4 & 0.7 \\
\hline 356 & 1.7 & 0.9 & 1.5 & 2.1 & 0.8 & 1.7 & 2.1 & 0.8 & 1.7 \\
\hline 361 & 0.0 & 0.9 & 0.0 & 0.0 & 0.8 & 0.0 & 0.4 & 1.0 & 0.4 \\
\hline 390 & 2.4 & 2.9 & 6.9 & 2.0 & 2.6 & 5.2 & 1.7 & 2.7 & 4.6 \\
\hline BI & 1.0 & 1.4 & 1.4 & 1.1 & 1.5 & 1.6 & 0.9 & 1.7 & 1.6 \\
\hline 321 & \begin{tabular}{|l|}
7.2 \\
\end{tabular} & 0.6 & 4.4 & 6.8 & 0.6 & 4.1 & 6.4 & 0.7 & 4.3 \\
\hline 323 & 2.0 & 0.3 & 0.6 & 3.6 & 0.4 & 1.3 & 1.7 & 0.6 & 1.0 \\
\hline Э31 & 0.2 & 0.7 & 0.1 & 0.2 & 0.6 & 0.2 & 0.6 & 0.6 & 0.3 \\
\hline 341 & 1.8 & 4.4 & 8.0 & 2.0 & 4.3 & 8.7 & 2.5 & 3.5 & 8.7 \\
\hline 351 & 0.3 & 5.4 & 1.7 & 0.3 & 5.7 & 1.6 & 0.3 & 6.0 & 1.5 \\
\hline 352 & 1.3 & 1.2 & 1.5 & 1.5 & 1.2 & 1.7 & 1.3 & 1.2 & 1.6 \\
\hline 353 & 0.1 & 1.6 & 0.2 & 0.2 & 1.7 & 0.4 & 0.1 & 3.1 & 0.4 \\
\hline 354 & 2.1 & 0.0 & 0.1 & 2.2 & 0.0 & 0.1 & 0.8 & 0.1 & 0.1 \\
\hline 355 & 0.0 & 1.3 & 0.0 & 0.0 & 1.1 & 0.0 & 0.0 & 1.1 & 0.0 \\
\hline 362 & 0.0 & 6.7 & 0.2 & 0.0 & 5.4 & 0.2 & 0.0 & 3.1 & 0.1 \\
\hline 369 & 0.4 & 0.1 & 0.1 & 1.3 & 0.2 & 0.2 & 0.6 & 0.1 & 0.1 \\
\hline 371 & 0.1 & 2.7 & 0.3 & 0.1 & 4.7 & 0.5 & 0.3 & 3.5 & 1.0 \\
\hline 372 & 3.3 & 3.7 & 12.0 & 3.0 & 4.9 & 14.7 & 3.1 & 4.0 & 12.4 \\
\hline 381 & 1.0 & 1.5 & 1.4 & 0.9 & 2.1 & 2.0 & 1.2 & 2.0 & 2.3 \\
\hline BCDK & 0.2 & 3.6 & 0.6 & 0.2 & 4.2 & 0.8 & 0.3 & 3.9 & 1.0 \\
\hline 332 & 3.1 & 0.1 & 0.3 & 9.6 & 0.1 & 0.8 & 8.5 & 0.0 & 0.4 \\
\hline 382 & 0.2 & 7.0 & 1.3 & 0.2 & 7.3 & 1.7 & 0.3 & 5.5 & 1.4 \\
\hline 383 & 0.3 & 2.2 & 0.6 & 0.3 & 3.3 & 1.1 & 0.6 & 3.0 & 1.8 \\
\hline 384 & 0.0 & 39.6 & 0.9 & 0.0 & 45.8 & 0.7 & 0.0 & 34.3 & 0.6 \\
\hline 385 & 0.3 & 0.7 & 0.2 & 0.3 & 0.8 & 0.2 & 0.2 & 1.9 & 0.4 \\
\hline Indust. & 0.4 & 2.1 & 0.8 & 0.6 & 2.3 & 1.3 & 0.6 & 2.4 & 1.3 \\
\hline
\end{tabular}

Fuente: Morán y Contreras (1992), Anexo 15.

$\mathrm{BCND}=$ Bienes de Consumo no Duraderos

$\mathrm{BI}=$ Bienes Intermedios

BCDK= Bienes de Consumo Duradero y de Capital 
tipo de productos una demanda poco dinámica dentro del mercado internacional. Dentro de esta rama, es la subrama de bebidas la de mayor importancia competitiva, aunque ésta se ha visto disminuida a través del período, lo que le ha significado a 1990 un índice inferior a la unidad, denotando una pérdida de competitividad.

\section{Penetración relativa de las Importaclones}

El indicador de penetración relativa de importaciones del sector industrial arroja cifras superiores a la unidad, lo que denota una alta incidencia de importaciones de productos industriales en el mercado local. Esta siluación ha tenido un carácter ascendente, como bien se puede apreciar en el cuadro 15.

Cuadro 15

Penetración relativa de Importaclones según ramas Industriales

\begin{tabular}{|cccc|}
\hline $\begin{array}{c}\text { Codigo } \\
\text { Rama }\end{array}$ & 1988 & 1989 & 1990 \\
\hline 31 & 0.3 & 0.3 & 0.4 \\
32 & 0.7 & 0.7 & 1.2 \\
33 & 0.3 & 0.3 & 0.4 \\
34 & 1.7 & 1.8 & 1.9 \\
35 & 1.5 & 1.5 & 1.6 \\
36 & 0.5 & 0.5 & 0.5 \\
37 & 1.4 & 1.6 & 1.6 \\
38 & 1.7 & 1.7 & 1.8 \\
39 & 1.7 & 1.5 & 1.6 \\
\hline Promedio & & & \\
Industrial & 3.5 & 3.6 & 4.0 \\
\hline
\end{tabular}

Fuente: Morán y Contreras (1992), Anexo 12.

La siluación se explica con mayor claridad cuando observamos el alto porcentaje que muestran las imporlaciones del sector dentro del consumo aparente, porcentaje que se incementó de $54.8 \%$ a $62.5 \%$ entre 1988 y 1990, como se se ve en el cuadro 16. 


\section{Cuadro 16 \\ Participación de las importaciones \\ dentro del consumo aparente según ramas Industrlales}

(\%)

\begin{tabular}{|cccc|}
\hline $\begin{array}{c}\text { Código } \\
\text { Rama }\end{array}$ & 1988 & 1989 & 1990 \\
\hline 31 & 18.3 & 18.1 & 21.3 \\
32 & 38.4 & 40.2 & 62.9 \\
33 & 18.3 & 18.1 & 20.0 \\
34 & 94.1 & 96.6 & 106.6 \\
35 & 82.3 & 84.3 & 89.8 \\
36 & 25.8 & 25.4 & 25.8 \\
37 & 78.6 & 86.9 & 90.0 \\
38 & 94.1 & 95.5 & 96.9 \\
39 & 90.5 & 79.7 & 87.3 \\
\hline Promedio & & & \\
Industrial & 54.8 & 56.1 & 62.5 \\
Pais & 15.8 & 16.2 & 19.7 \\
\hline
\end{tabular}

Fuente: Morán y Contreras (1992), Anexo 12.

Toda esta situación se vuelve más preocupante, en lo que se refiere a nuestra dependencia de las imporlaciones, cuando vemos que no sólo es el hecho que se incrementen las importaciones, sino que además la tendencia de suplir con importaciones nuestro consumo adicional va en aumento, lo cual podemos observar en el cuadro 17, a través del índice que denominamos Abastecimiento del Mercado Interno, donde los incrementos en las importaciones superan los incrementos que se dan en el consumo aparente; y esto además es el caso para toda la economia.

Si vemos el análisis a través de las ramas que componen el seclor (cuadros 15, 16 y 17), a excepción de Alimentos, Bebidas y Tabaco (CIIU 31), Madera (CIIU 33) y Minerales no Metálicos (CIIU 36), el resio mantienen el mismo comportamienlo de la industria en su tolalidad: los indices de penetración relativa de importaciones reflejan cifras arriba de la unidad, el porcentaje del mercado local que se cubre con importaciones está arriba del coeficiente del sector y la tendencia es cada vez más a abastecer nuestro mercado interno con importaciones. 


Cuadro 17
Abastecimlento del mercado Interno
sector Industrlal
\begin{tabular}{|lll|}
\hline \multicolumn{3}{|c}{ Código } \\
Rama & 1989 & 1990 \\
\hline 31 & 0.9 & 1.8 \\
32 & 1.3 & 3.8 \\
33 & 0.9 & 1.6 \\
34 & 1.2 & 1.7 \\
35 & 1.2 & 1.1 \\
36 & 0.9 & 1.1 \\
37 & 1.3 & 1.2 \\
38 & 1.1 & 1.1 \\
39 & 0.6 & 1.3 \\
\hline Industria & 1.1 & 1.4 \\
País & 1.1 & 1.9 \\
\hline
\end{tabular}

Fuente: Morán y Conlreras (1992), Anexo 12.

Cabe destacar que aún aquellas ramas que presenlan indices de penetración de importaciones abajo de la unidad, como son las excepciones mencionadas en el párrafo anterior, para 1990 también muestran una tendencia hacia el abastecimienlo del mercado local con importaciones (ver cuadro 17).

A nivel de subramas y como se muesira en los cuadros 18,19 y 20 , las subramas de Bebidas, Tabaco, Derivados de Petróleo y Carbón, Minerales no metálicos y Muebles, presentan Indices de penetración de imporlaciones baslante por debajo de la unidad, lo que signitica que el mercado local de estos productos tiene una mínima penetración de importaciones; para estas subramas, el indice sobre participación de las importaciones dentro del consumo aparente, oscila entre el $1 \%$ y $10 \%$.

Algunas olras subramas, representan casi el $100 \%$ ó arriba del $100 \%$ su participación de importaciones denlro del consumo local, lo que denota una nula o casi nula participación de nuestra producción. 
Cuadro 18

Participación de las Importaciones dentro del consumo aparente según categoria de destino

\begin{tabular}{|c|c|c|c|c|}
\hline Código & $\begin{array}{l}\text { Soncepto } \\
\qquad \text { Bienes/Ramas }\end{array}$ & 1988 & 1989 & 1990 \\
\hline \multicolumn{2}{|c|}{ A. Bienes de consumo no duraderos } & 21.6 & 21.4 & 25.5 \\
\hline 311 & Alimentos & 25.3 & 24.6 & 28.7 \\
\hline 313 & Bebidas & 1.7 & 2.3 & 3.6 \\
\hline 314 & Tabaco & 4.2 & 4.1 & 4.0 \\
\hline 322 & Prendas de vestir & 8.7 & 11.9 & 28.3 \\
\hline 324 & Calzado & 42.5 & 45.3 & 65.7 \\
\hline 342 & Imprenla & 27.7 & 27.8 & 29.5 \\
\hline 356 & Productos de plásticos & 94.0 & 97.3 & 100.3 \\
\hline 361 & Barro y porcelana & 43.2 & 43.5 & 52.8 \\
\hline 390 & Diversos & 90.5 & 79.7 & 87.3 \\
\hline \multicolumn{2}{|c|}{ B. Bienes intermedios } & 75.4 & 77.8 & 85.4 \\
\hline 321 & Texliles & 68.1 & 65.5 & 99.1 \\
\hline 323 & Cueros & 15.4 & 14.8 & 35.2 \\
\hline 331 & Madera caña y corcho & 27.8 & 29.0 & 32.5 \\
\hline 341 & Papel y cartón & 121.8 & 129.1 & 150.9 \\
\hline 351 & Suslancias quimicas & 99.6 & 99.1 & 99.8 \\
\hline 352 & Produclos quimicos & 90.9 & 91.6 & 95.9 \\
\hline 353 & Relinerias de Petróleo & 66.8 & 69.2 & 83.2 \\
\hline 354 & Derivados de petróleo y carbón & 1.6 & 2.7 & 6.9 \\
\hline 355 & Caucho & 79.9 & 78.1 & 79.5 \\
\hline 362 & Vidrio y sus productos & 86.1 & 84.5 & 83.0 \\
\hline 369 & Minerales no metálicos & 8.3 & 8.9 & 9.6 \\
\hline 371 & Hierro y acero & 68.8 & 77.4 & 78.7 \\
\hline 372 & Metales no ferrosos & 124.8 & 137.9 & 148.5 \\
\hline 381 & Produclos metálicos & 101.0 & 104.3 & 109.4 \\
\hline \multicolumn{2}{|c|}{ C. Bienes de consumo duradero y capital } & 88.7 & 89.7 & 90.3 \\
\hline 332 & Muebles & 3.4 & 1.5 & 1.2 \\
\hline 382 & Maquinaria no eléctrica & 97.4 & 98.6 & 98.2 \\
\hline 383 & Maquinaria y aparalos eléclricos & 79.0 & 82.5 & 85.4 \\
\hline 384 & Equipo de transporte & 96.8 & 96.9 & 96.6 \\
\hline 385 & Equipo cientilico & 102.7 & 100.5 & 102.0 \\
\hline \multicolumn{2}{|c|}{ Total industria } & 54.8 & 56.1 & 62.5 \\
\hline
\end{tabular}

Fuenle: Morán y Contreras (1992), Anexo 15 


\section{Cuadro 19}

Abastecimlento del mercado Interno

según categorla de destino

\begin{tabular}{|c|c|c|c|}
\hline \multicolumn{2}{|c|}{ Conceplo } & \multirow[b]{2}{*}{1989} & \multirow[b]{2}{*}{1990} \\
\hline Código & Bienes/Ramas & & \\
\hline \multicolumn{2}{|c|}{ A. Blenes de consumo no duraderos } & 1.0 & 1.8 \\
\hline 311 & Alimentos & 0.9 & 1.7 \\
\hline 313 & Bebidas & 3.2 & 3.4 \\
\hline 314 & Tabaco & 0.7 & 0.9 \\
\hline 322 & Prendas de vestir & 6.2 & 7.7 \\
\hline 324 & Calzado & 5.0 & 2.9 \\
\hline 342 & Imprenla & 1.0 & 1.2 \\
\hline 356 & Productos de plásticos & 1.4 & 1.1 \\
\hline 361 & Barro y porcelana & 1.0 & 1.8 \\
\hline 390 & Diversos & 0.6 & 1.3 \\
\hline \multicolumn{2}{|c|}{ B. Bienes intermedios } & 1.2 & 1.3 \\
\hline 321 & Textiles & 0.8 & 5.3 \\
\hline 323 & Cueros & 0.8 & 5.2 \\
\hline 331 & Madera cańa y corcho & 1.2 & 1.7 \\
\hline 341 & Papel y cartón & 1.5 & 2.7 \\
\hline 351 & Sustancias quimicas & 1.0 & 1.0 \\
\hline 352 & Produclos químicos & 1.0 & 1.2 \\
\hline 353 & Refinerías de Petróleo & 1.5 & 1.4 \\
\hline 354 & Derivados de pelróleo y carbón & 131.0 & 6.4 \\
\hline 355 & Caucho & 0.7 & 1.1 \\
\hline 362 & Vidrio y sus produclos & 0.9 & 0.9 \\
\hline 369 & Minerales no metálicos & 1.4 & 1.4 \\
\hline 371 & Hierro y acero & 1.4 & 1.1 \\
\hline 372 & Melales no ferrosos & 1.4 & 1.4 \\
\hline 381 & Productos metálicos & 1.1 & 1.5 \\
\hline \multicolumn{2}{|c|}{ C. Blenes de consumo duradero y capltal } & 1.1 & 1.1 \\
\hline 332 & Muebles & (1.6) & $(0.1)$ \\
\hline 382 & Maquinaria no eléctrica & 1.1 & 1.0 \\
\hline 383 & Maquinaria y aparalos eléctricos & 1.2 & 1.3 \\
\hline 384 & Equipo de Iransporte & 1.0 & 1.0 \\
\hline 385 & Equipo cienlífico & 0.9 & 1.0 \\
\hline
\end{tabular}

Fuente: Morán y Contreras (1992), Anexo 16 
Cuadro 20

Penetración relativa de Importaclones

según calegoria de destino

\begin{tabular}{|c|c|c|c|c|}
\hline \multicolumn{2}{|c|}{ Conceplo } & \multirow[b]{2}{*}{1988} & \multirow[b]{2}{*}{1989} & \multirow[b]{2}{*}{1990} \\
\hline Código & Bienes/Ramas & & & \\
\hline \multicolumn{2}{|c|}{ A. Blenes de consumo no duraderos } & 0.4 & 0.4 & 0.5 \\
\hline 311 & Alimentos & 0.5 & 0.5 & 0.5 \\
\hline 313 & Bebidas & 0.0 & 0.0 & 0.1 \\
\hline 314 & Tabaco & 0.1 & 0.1 & 0.1 \\
\hline 322 & Prendas de vestir & 0.2 & 0.2 & 0.5 \\
\hline 324 & Calzado & 0.8 & 0.8 & 1.2 \\
\hline 342 & Imprenla & 0.5 & 0.5 & 0.5 \\
\hline 356 & Produclos de plásticos & 1.7 & 1.8 & 1.8 \\
\hline 361 & Barro y porcelana & 0.8 & 0.8 & 1.0 \\
\hline 390 & Diversos & 1.7 & 1.5 & 1.6 \\
\hline \multicolumn{2}{|c|}{ B. Bienes Intermedios } & 1.4 & 1.4 & 1.6 \\
\hline 321 & Textiles & 1.2 & 1.2 & 1.8 \\
\hline 323 & Cueros & 0.3 & 0.3 & 0.6 \\
\hline 331 & Madera caña y corcho & 0.5 & 0.5 & 0.6 \\
\hline 341 & Papel y cartón & 2.2 & 2.4 & 2.8 \\
\hline 351 & Sustancias químicas & 1.8 & 1.8 & 1.8 \\
\hline 352 & Productos químicos & 1.7 & 1.7 & 1.8 \\
\hline 353 & Relinerías de Petróleo & 1.2 & 1.3 & 1.5 \\
\hline 354 & Derivados de petróleo y carbón & 0.0 & 0.1 & 0.1 \\
\hline 355 & Caucho & 1.5 & 1.4 & 1.5 \\
\hline 362 & Vidrio y sus productos & 1.6 & 1.5 & 1.5 \\
\hline 369 & Minerales no melálicos & 0.2 & 0.2 & 0.2 \\
\hline 371 & Hierro y acero & 1.3 & 1.4 & 1.4 \\
\hline 372 & Melales no lerrosos & 2.3 & 2.5 & 2.7 \\
\hline 381 & Producios melálicos & 1.8 & 1.9 & 2.0 \\
\hline \multicolumn{2}{|c|}{ C. Bienes de consumo duradero y capltal } & 1.6 & 1.6 & 1.7 \\
\hline 332 & Muebles & 0.1 & 0.0 & 0.0 \\
\hline 382 & Maquinaria no eléctrica & 1.8 & 1.8 & 1.8 \\
\hline 383 & Maquinaria y aparatos eléctricos & 1.4 & 1.5 & 1.6 \\
\hline 384 & Equipo de transporte & 1.8 & 1.8 & 1.8 \\
\hline 385 & Equipo cientílico & 1.9 & 1.8 & 1.9 \\
\hline \multicolumn{2}{|c|}{ Total Industria } & 3.5 & 3.6 & 4.0 \\
\hline
\end{tabular}

Fuente: Morán y Contreras (1992), Anexo 15 


\subsection{Análisls global}

En general, la competitividad de nuestra industria, vista a Iravés de los distinlos indices utilizados, presenta una situación bastante deslavorable, puesto que el sector sigue siendo deficitario, la penetración relativa de las importaciones se ha incrementado, y aunque la industria presente una compelitividad aparente sobre otros sectores, ésta es producto del incremento en su apertura externa, que es influenciada principalmente por las importaciones. Esto disminuye la importancia del resultado positivo, ya que éste, no es por eleclo de sus exportaciones, sino por las importaciones de productos demandados de ese sector.

A nivel de ramas induslriales, es la de Textiles y Cuero (CIIU 32) la que presenta un mejor resultado, lomando en consideración lodos los índices de competitividad, y sobre todo es la única rama con un saldo de comercio superavitario. Sin embargo, hay que hacer nolar que la penetración relativa de sus imporlaciones eslá por arriba de la unidad y su tendencia es a incrementarse, lo cual es preocupante, ya que denota una demanda mayor de productos importados de este sector.

Las industrias de Papel, Imprenta y Editoriales (CIIU 34) y Metálicas Básicas (CIIU 37) tienen algunos resultados que cabe destacar, como son sus indices de compelitividad aparenle arriba del de otras ramas, y donde tanto su ventaja comparaliva y apertura exlerna se reluerzan con resultados arriba de la unidad. No obstante, su actividad es deficitaria, aunque menor que el de otras ramas, y por otro lado la incidencia de las importaciones en el mercado local de productos de estas ramas es alto y con un carácter ascendenle.

A nivel de subramas, las de Bebidas (CIIU 313), Prendas de Vestir (CIIU 322), Calzado (CIIU 324), Textiles (CIIU 321), Muebles (CIIU 332), Papel y Cartón (CIIU 341), y Melales no Ferrosos (CIIU 372), presentan en alguna medida indices positivos de competitividad. Las primeras cin$c o$, muestran actividades superavitarias, y además las de Bebidas, Prendas de Vestir y Muebles, presenlan una baja penetración de importaciones, lo que denola satislacción del mercado local con la producción nacional; y las últimas dos, Papel y Carnón y Metales no Ferrosos por la competitividad aparente que muestran sobre el reslo de subramas.

En cuanto a la demanda de nuestra producción en el mercado internacional o polencial exportador, vislo a través del Coeficiente de Exportaciones, nos presenta que las ramas de Papel, Imprenta y Editoriales (CIIU 34), Metálicas Básicas (CIIU 37), Produclos Melálicos, Maquinaria y Equipo (CIIU 38) y Textiles y Cuero (CIIU 32), son las que destinan un porcentaje mayor de su producción al mercado internacional, siendo las 
más significalivas las de Papel, Imprenla y Editoriales, y Melálicas Básicas. No obstante, eslas no figuran dentro de las más importanles en la estructura de nuestras exporlaciones, donde la primera ocupa el cuarlo lugar y la segunda el sexlo de un total de nueve ramas induslriales; y mucho menos imporlantes son en el valor agregado, pero su ulilización de mano de obra revisle importancia en relación con el resto de ramas industriales (Véase anexo).

A nivel de subramas y con las mismas caracleristicas de las ramas anteriores, las de Metales No Ferrosos (CIIU 372) y Papel y Cartón (CIIU 341), presenlan los mayores coeficientes de exportación. En lo relerente a la importancia de las dilerentes ramas de la induslria en los indices agregados (veáse anexo), lenemos que denlro del Valor Agregado $y$ las Exportaciones, las de Alimentos, Bebidas y Tabaco (CIIU 31), Textiles y Cuero (CIIU 32) e Industria Quimicas (CIIU 35) son las más importantes. A nivel de subramas las de Alimentos (CIIU 311) y Bebidas (CIIU 313), lo son denlro del Valor Agregado: y las de Alimenlos (CIIU 311), Textiles (CIIU 321), Produclos Quimicos (CIIU 352) y Papel y Cartón (CIIU 341) dentro de las exporlaciones.

\section{Conclusiones}

1. Duranle los años 1989 y 1990 , la induslria manulaclurera experimentó un incremento significativo en su participación denlro de las exportaciones, debido, por una parte, a la disminución de las exportaciones del sector agropecuario (całé) y, por otra, al incremento en el volumen de sus propias exporlaciones.

2. Tomando en consideración los resultados de la evaluación sobre la competitividad inlernacional de nuestra industria, podemos concluir que el seclor es altamenle deficilario en su comercio internacional y liene un allo grado de penetración de las imporlaciones. En consecuencia, de acuerdo con el crilerio utilizado en este trabajo, podemos definirlo como ineficienle, ya que, en primer lugar, no es una industria capaz de exportar ni siquiera lo necesario para suplir las necesidades de importaciones de bienes industriales que requiere el pais; y en segundo lugar, la demanda doméstica de consumo está dominada por productos imporlados.

3. Estos resultados, unidos a la situación actual de la economia y el entorno internacional, ponen de manifiesto la necesidad de pensar seriamente en llevar a cabo un programa de reconversión industrial en nuestro pais. Una reconversión, insistimos, basada en el desarrollo económico global y no de una empresa en particular, ya que hasla ahora la política de liberalización tolal e iniciativa empresarial no ha 
logrado desarrollar una competitividad internacional aceplable para la economía en su totalidad ni para la industria en particular, como lo demuestran los resultados de la evaluación.

\section{REFERENCIAS BIBLIOGRAFICAS}

Coriat, Benjamin (1989), "Le Débat Theorique Sur de la Desindustrializacion: Argumenls, Enjeux el Perspectives". Economie Europeenne.

Del Belio, Juan Carlos (1990). "Pautas para estudiar la Competitividad Internacional de Actividades Industriales Seleccionadas" Programa de Reconversión Industrial: Costa Rica. Instituto Centroamericano de Administración de Empresas (INCAE) (1991), "Desgravación Arancelaria, Promoción de Exportaciones y Transiormación Productiva: un Enloque Integral".

Morán, Yolanda y Linet Contreras (1992). Competitividad Internacional. Hacia un Proceso de Reconversión Industrial. Tesis de grado (Economla), Universidad Centroamericana José Simeón Cañas, San Salvador.

Rivera Campos, Roberto (1983). La Concentración Manufacturera Salvadoreña: Un Intento de Cuantificación. Tesis de grado (Económia), Universidad Centroamericana José Simeón Cañas, San Salvador.

Salazar Xirinachs, José Manuel (1990), "El Salvador, Recomendaciones para la Elaboración de una Nueva Estrategia de Desarrollo Industrial y Propuesia de un Programa de Reconversión Industrial". San Salvador: Mimeo. 


\section{ANEXO}

\section{ALGUNOS DATOS COMPLEMENTARIOS SOBRE EL SECTOR INDUSTRIAL SALVADOREÑO}

\section{Cuadro A1}

Estructura del valor agregado por rama (\%)

\begin{tabular}{|crrrr|}
\hline $\begin{array}{c}\text { CODIGO } \\
\text { RAMA }\end{array}$ & 1988 & 1989 & 1990 \\
\hline 31 & 57.5 & 57.4 & 57.6 \\
32 & 11.5 & 11.7 & 11.6 \\
33 & 2.9 & 3.0 & 2.8 \\
34 & 2.9 & 3.0 & 3.1 \\
35 & 13.0 & 12.7 & 12.8 \\
36 & 5.3 & 5.4 & 5.3 \\
37 & 2.7 & 2.6 & 2.7 \\
38 & 3.8 & 3.8 & 3.8 \\
39 & 0.5 & 0.5 & 0.5 \\
\hline
\end{tabular}

Fuente: Morán y Contreras, anexo 11 


\section{Cuadro A2 \\ Estructura del valor agregado Industrlal según categoria de destino}

(\%)

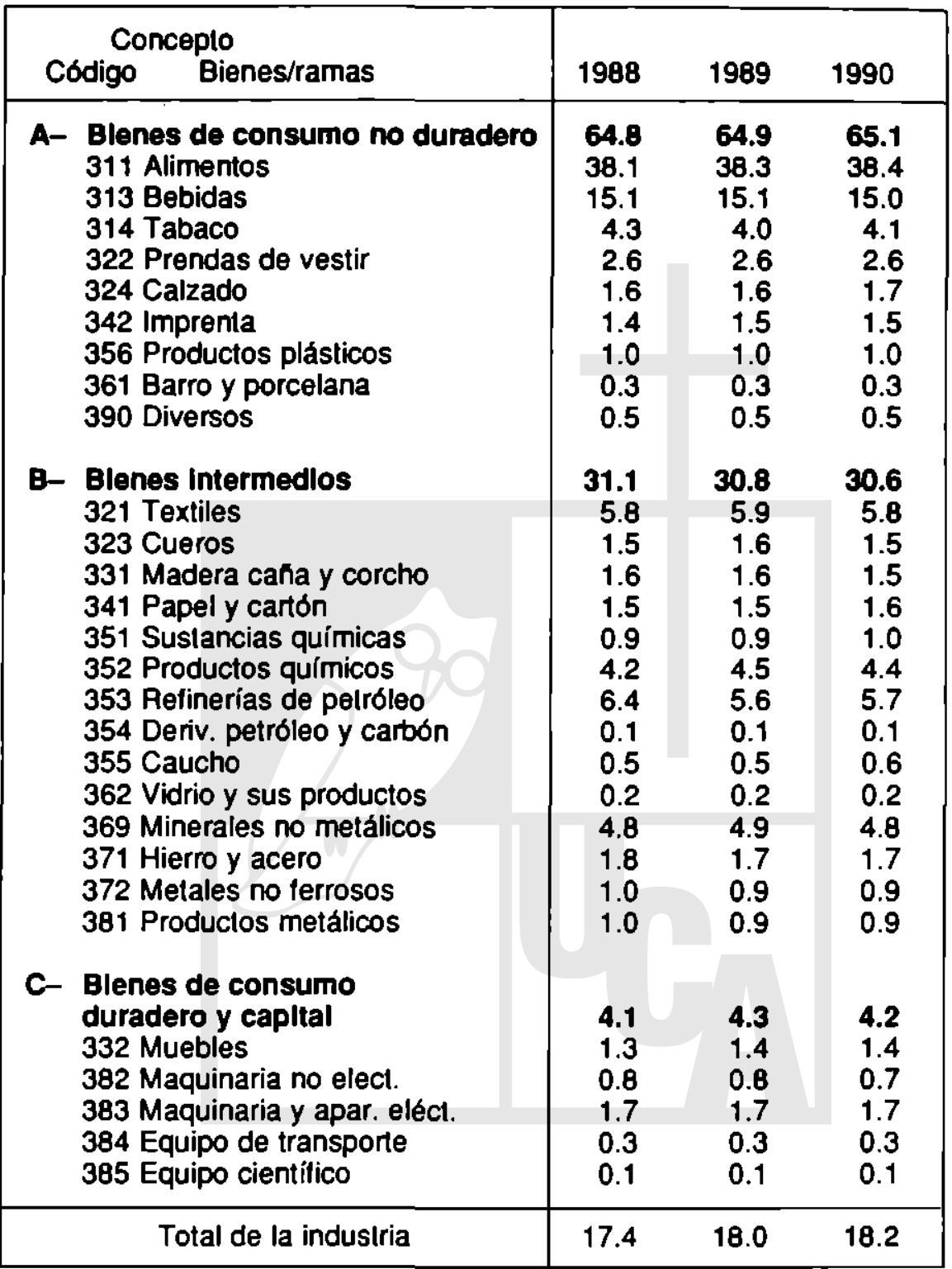

Fuente: Morán y Contreras, anexo 14 


\section{Cuadro A3 \\ Estructura de las exportaclones por rama (\%)}

\begin{tabular}{|ccrr|}
\hline $\begin{array}{c}\text { CODIGO } \\
\text { RAMA }\end{array}$ & 1988 & 1989 & 1990 \\
\hline 31 & 27.7 & 22.2 & 22.8 \\
32 & 24.4 & 25.2 & 27.1 \\
33 & 0.3 & 0.4 & 0.4 \\
34 & 10.5 & 11.0 & 10.9 \\
35 & 21.8 & 24.2 & 21.9 \\
36 & 0.2 & 0.7 & 0.4 \\
37 & 5.5 & 6.1 & 6.1 \\
38 & 8.1 & 9.1 & 9.2 \\
39 & 1.6 & 1.3 & 1.1 \\
\hline Total & 38.7 & 53.4 & 52.8 \\
\hline
\end{tabular}

Fuente: Morán y Contreras, anexo 11 


\section{Cuadro A4 \\ Estructura de las exportaclones industriales según categoría de destino}

(\%)

\begin{tabular}{|c|c|c|c|}
\hline $\begin{array}{l}\text { Concepto } \\
\text { Código } \quad \text { Bienes/ramas }\end{array}$ & 1988 & 1989 & 1990 \\
\hline $\begin{array}{l}\text { A- Blenes de consumo no duradero } \\
311 \text { Alimenlos } \\
313 \text { Bebidas } \\
314 \text { Tabaco } \\
322 \text { Prendas de vestir } \\
324 \text { Calzado } \\
342 \text { Imprenta } \\
\text { 356 Productos plásticos } \\
\text { 361 Barro y porcelana } \\
\text { 390 Diversos }\end{array}$ & $\begin{array}{r}38.7 \\
23.9 \\
3.6 \\
0.1 \\
1.5 \\
3.5 \\
1.0 \\
3.4 \\
0.0 \\
1.6\end{array}$ & $\begin{array}{r}34.8 \\
19.0 \\
3.2 \\
0.0 \\
2.6 \\
4.0 \\
1.0 \\
3.8 \\
0.0 \\
1.3\end{array}$ & $\begin{array}{r}35.8 \\
19.8 \\
3.0 \\
0.1 \\
3.4 \\
4.1 \\
0.9 \\
3.4 \\
0.1 \\
1.1\end{array}$ \\
\hline $\begin{array}{l}\text { B- Blenes Intermedlos } \\
321 \text { Textiles } \\
323 \text { Cueros } \\
331 \text { Madera cafia y corcho } \\
341 \text { Papel y carón } \\
351 \text { Sustancias químicas } \\
352 \text { Productos químicos } \\
353 \text { Refinerias de petróleo } \\
\text { 354 Deriv. petróleo y carbón } \\
355 \text { Caucho } \\
\text { 362 Vidrio y sus productos } \\
369 \text { Minerales no melálicos } \\
371 \text { Hierro y acero } \\
372 \text { Metales no lerrosos } \\
381 \text { Productos metálicos }\end{array}$ & $\begin{array}{r}57.1 \\
18.8 \\
0.6 \\
0.1 \\
9.5 \\
3.4 \\
13.1 \\
1.8 \\
0.0 \\
0.1 \\
0.0 \\
0.2 \\
0.4 \\
5.1 \\
4.0\end{array}$ & $\begin{array}{r}60.1 \\
17.7 \\
0.9 \\
0.2 \\
10.0 \\
3.3 \\
14.3 \\
2.8 \\
0.0 \\
0.0 \\
0.1 \\
0.6 \\
0.6 \\
5.5 \\
4.3\end{array}$ & $\begin{array}{r}58.8 \\
18.6 \\
1.0 \\
0.3 \\
10.1 \\
3.0 \\
12.7 \\
2.8 \\
0.0 \\
0.1 \\
0.0 \\
0.3 \\
1.2 \\
4.9 \\
4.0\end{array}$ \\
\hline $\begin{array}{l}\text { C- Blenes de consumo } \\
\text { duradero y capltal } \\
332 \text { Muebles } \\
382 \text { Maquinaria no elect. } \\
383 \text { Maquinaria y apar. eléct. } \\
384 \text { Equipo de transporte } \\
385 \text { Equipo cientítico }\end{array}$ & $\begin{array}{l}4.2 \\
0.2 \\
1.9 \\
1.4 \\
0.2 \\
0.5\end{array}$ & $\begin{array}{l}5.0 \\
0.2 \\
2.4 \\
1.9 \\
0.2 \\
0.4\end{array}$ & $\begin{array}{l}5.3 \\
0.1 \\
1.9 \\
2.7 \\
0.1 \\
0.5\end{array}$ \\
\hline Total de la industria & 38.7 & 53.4 & 52.8 \\
\hline
\end{tabular}

Fuente: Morán y Contreras, anexo 14 


\section{Cuadro A5}

Estructura de las Importaclones (\%)

\begin{tabular}{|crrr|}
\hline $\begin{array}{c}\text { CODIGO } \\
\text { RAMA }\end{array}$ & 1988 & 1989 & 1990 \\
\hline 31 & 12.4 & 12.0 & 11.9 \\
32 & 3.7 & 3.7 & 4.6 \\
33 & 0.7 & 0.7 & 0.6 \\
34 & 5.6 & 5.4 & 4.6 \\
35 & 38.6 & 36.4 & 45.8 \\
36 & 2.0 & 1.9 & 1.6 \\
37 & 5.6 & 7.4 & 5.9 \\
38 & 30.8 & 31.9 & 24.3 \\
39 & 0.7 & 0.7 & 0.7 \\
\hline Tolal & 395.4 & 96.4 & 95.4 \\
\hline
\end{tabular}

Fuenle: Morán y Contreras, anexo 11 


\section{Cuadro A6}

Estructura de las Importaciones Industrlales según categorla de destino

(\%)

\begin{tabular}{|c|c|c|c|c|}
\hline & $\begin{array}{l}\text { Conceplo } \\
\text { digo Bienes/ramas }\end{array}$ & 1988 & 1989 & 1990 \\
\hline A- & $\begin{array}{l}\text { Blenes de consumo no duradero } \\
311 \text { Alimentos } \\
313 \text { Bebidas } \\
314 \text { Tabaco } \\
322 \text { Prendas de vestir } \\
\text { 324 Calzado } \\
342 \text { Imprenta } \\
\text { 356 Produclos plásticos } \\
\text { 361 Barro y porcelana } \\
\text { 390 Diversos }\end{array}$ & $\begin{array}{r}16.6 \\
11.9 \\
0.3 \\
0.2 \\
0.2 \\
0.6 \\
0.5 \\
2.0 \\
0.3 \\
0.7\end{array}$ & $\begin{array}{r}16.0 \\
11.5 \\
0.4 \\
0.2 \\
0.3 \\
0.5 \\
0.5 \\
1.8 \\
0.3 \\
0.7\end{array}$ & $\begin{array}{r}16.1 \\
11.3 \\
0.5 \\
0.2 \\
0.5 \\
0.6 \\
0.5 \\
1.6 \\
0.3 \\
0.7\end{array}$ \\
\hline B- & $\begin{array}{l}\text { Blenes Inlermedlos } \\
\text { 321 Textiles } \\
\text { 323 Cueros } \\
\text { 331 Madera cafia y corcho } \\
\text { 341 Papel y cartón } \\
\text { 351 Sustancias quimicas } \\
\text { 352 Produclos químicos } \\
\text { 353 Refinerias de petróleo } \\
\text { 354 Deriv. pelróleo y carbón } \\
\text { 355 Caucho } \\
\text { 362 Vidrio y sus productos } \\
\text { 369 Minerales no metálicos } \\
\text { 371 Hierro y acero } \\
\text { 372 Metales no ferrosos } \\
\text { 381 Productos metálicos }\end{array}$ & $\begin{array}{r}56.8 \\
2.6 \\
0.3 \\
0.6 \\
5.1 \\
11.2 \\
10.2 \\
13.0 \\
0.0 \\
2.2 \\
1.3 \\
0.5 \\
4.0 \\
1.6 \\
4.3\end{array}$ & $\begin{array}{r}56.7 \\
2.6 \\
0.3 \\
0.7 \\
4.9 \\
11.4 \\
9.8 \\
11.6 \\
0.0 \\
1.9 \\
1.1 \\
0.5 \\
5.6 \\
1.9 \\
4.6\end{array}$ & $\begin{array}{r}63.0 \\
2.9 \\
0.6 \\
0.6 \\
4.1 \\
11.9 \\
9.5 \\
21.0 \\
0.0 \\
1.8 \\
0.9 \\
0.4 \\
4.4 \\
1.6 \\
3.4\end{array}$ \\
\hline C- & $\begin{array}{l}\text { Blenes de consumo } \\
\text { duradero y capltal } \\
332 \text { Muebles } \\
382 \text { Maquinaria no elect. } \\
383 \text { Maquinaria y apar. eléct. } \\
\text { 384 Equipo de transporte } \\
\text { 385 Equipo científico }\end{array}$ & $\begin{array}{r}26.6 \\
0.1 \\
10.1 \\
5.4 \\
9.5 \\
1.5\end{array}$ & $\begin{array}{r}27.3 \\
0.0 \\
10.0 \\
5.9 \\
10.0 \\
1.5\end{array}$ & $\begin{array}{r}21.0 \\
0.0 \\
7.2 \\
4.4 \\
6.9 \\
2.4\end{array}$ \\
\hline & Tolal de la industria & 95.4 & 96.4 & 95.4 \\
\hline
\end{tabular}

Fuenle: Morán y Contreras, anexo 14 


\section{Cuadro A7 \\ Estructura del empleo y establecimlentos \\ por rama}

$(\%)$

\begin{tabular}{|l|c|c|c|c|}
\hline $\begin{array}{l}\text { Codigo } \\
\text { ramas }\end{array}$ & $\begin{array}{c}\text { Número de } \\
\text { empleados }\end{array}$ & $\begin{array}{c}\text { Estruct. } \\
(\%)\end{array}$ & $\begin{array}{c}\text { Número de. } \\
\text { estableclm. }\end{array}$ & $\begin{array}{c}\text { Estructu. } \\
(\%)\end{array}$ \\
\hline 31 & 18,981 & 36.3 & 523 & 33.4 \\
32 & 13,217 & 25.2 & 355 & 22.7 \\
33 & 1,416 & 2.7 & 79 & 5.0 \\
34 & 4,769 & 9.1 & 117 & 7.5 \\
35 & 6,048 & 11.5 & 144 & 9.2 \\
36 & 1,811 & 3.4 & 115 & 7.3 \\
37 & 877 & 1.7 & 20 & 1.3 \\
38 & 4,599 & 8.8 & 169 & 10.8 \\
39 & 626 & 1.2 & 43 & 2.7 \\
\hline TOTAL & 52,344 & 100.0 & 1,565 & 100.0 \\
\hline
\end{tabular}

Fuente: Morán y Conlreras, anexo 17.

\begin{tabular}{|c|c|c|c|c|}
\hline HAMAS & MICRO & PEQUEÑA & MEDIANA & GRANDE \\
\hline 31 & 44.7 & 31.5 & 15.9 & 7.8 \\
32 & 42.8 & 29.6 & 17.7 & 9.9 \\
33 & 58.2 & 30.4 & 7.6 & 3.8 \\
34 & 37.2 & 35.0 & 18.8 & 8.5 \\
35 & 21.5 & 38.9 & 26.4 & 13.2 \\
36 & 45.2 & 38.3 & 13.9 & 2.6 \\
37 & 15.0 & 50.0 & 20.0 & 15.0 \\
38 & 36.1 & 34.9 & 24.3 & 4.7 \\
39 & 44.2 & 32.6 & 20.9 & 2.3 \\
\hline TOTAL & 41.0 & 33.1 & 18.0 & 7.9 \\
\hline
\end{tabular}

Fuente: Morán y Contreras, anexo 17. 